The University of Maine

\title{
DigitalCommons@UMaine
}

Earth Science Faculty Scholarship

Earth Sciences

1981

\section{Tidal Flexure of Jakobshavns Glacier, West Greenland}

\author{
Craig S. Lingle \\ Terence J. Hughes \\ University of Maine - Main, terry.hughes@maine.edu \\ Ronald C. Kollmeyer
}

Follow this and additional works at: https://digitalcommons.library.umaine.edu/ers_facpub Part of the Earth Sciences Commons

\section{Repository Citation}

Lingle, Craig S.; Hughes, Terence J.; and Kollmeyer, Ronald C., "Tidal Flexure of Jakobshavns Glacier, West Greenland" (1981). Earth Science Faculty Scholarship. 114.

https://digitalcommons.library.umaine.edu/ers_facpub/114 


\title{
Tidal Flexure of Jakobshavns Glacier, West Greenland
}

\author{
Craig S. LINGLE
}

Geophysical and Polar Research Center, University of Wisconsin, Madison, Wisconsin 53706

TERENCE J. HugheS

Department of Geological Sciences, University of Maine, Orono, Maine 04469

RONALD C. KOLLMEYER

Department of Physical Sciences, United States Coast Guard Academy, New London, Connecticut 06320

\begin{abstract}
Jakobshavns Glacier, a floating outlet glacier on the West Greenland coast, was surveyed during July 1976. The vertical displacements of targets along two profiles perpendicular to the fjord wall bounding the north margin of the glacier were analyzed to determine the effect of flexure caused by tidal oscillations within the fjord. An analysis based on the assumption that vertical displacements of the glacier reflected pure elastic bending yielded the conclusion that the effective thickness of the ice (i.e., the thickness which remained unaffected by surface and basal cracking and which behaved as a continuum) was $\sim 160 \mathrm{~m} 2.6 \mathrm{~km}$ upglacier from the calving front and $\sim 110 \mathrm{~m} 0.6 \mathrm{~km}$ from the calving front. An analysis based on the more realistic assumption that observed bending reflected elastic and viscoplastic deformation yielded the conclusion that the average effective thickness of the ice was $316 \pm 74 \mathrm{~m}(\sim 40 \%$ of the estimated 800-m total thickness) $2.6 \mathrm{~km}$ from the calving front and $160 \pm 48 \mathrm{~m}$ ( $\sim 21 \%$ of the estimated $750-\mathrm{m}$ total) $0.6 \mathrm{~km}$ from the calving front. A constitutive relationship appropriate for hard glide during flexure was used.
\end{abstract}

\section{INTRODUCTION}

Jakobshavns is a floating outlet glacier located on the west coast of Greenland at latitude $69^{\circ} 10^{\prime} \mathrm{N}$ (Figure 1); it is fed by two ice streams that converge in Jakobshavns Fjord. Its discharge volume is approximately $26 \mathrm{~km}^{3} \mathrm{a}^{-1}$ [Carbonnell and Bauer, 1968], which is $11 \%$ of the estimated $240 \mathrm{~km}^{3} \mathrm{a}^{-1}$ iceberg discharge volume of the Greenland Ice Sheet.

The U.S. Coast Guard started the International Ice Patrol in 1914, because of the 1912 Titanic disaster, and Rear Admiral E. H. Smith expanded these observations of North Atlantic icebergs to include their West Greenland source areas. He conducted several expeditions to Davis Strait and Baffin Bay between 1928 and 1935 and identified Jakobshavns Glacier as the major source. One of us (R.C.K.) started the West Greenland Glacier Survey in 1968 to monitor iceberg production and the positions of the calving fronts of the outlet glaciers between Jakobshavns and Petermanns fjords. Observations of Jakobshavns Glacier were made in 1971, 1976, and 1978. The results of the 1976 survey are used in this analysis.

Amund Helland, a Norwegian geologist and surveyor, discovered the fast flow rates of the West Greenland outlet glaciers [Rink, 1877, p. 363]. Rink [1877, p. 369], who appears to have been the first to recognize West Greenland ice streams, suggested that flexure of floating outlet glaciers due to tide changes within the ice fjords might contribute to the formation of icebergs, which were well known among nineteenthcentury whalers as a serious hazard to navigation. More recently, Robin [1958] and Holdsworth [1969, 1977] have analyzed the problem of tidal bending of floating ice slabs and ice tongues, although in a rather different context. Hughes [1972, $1975,1977]$ has considered the effect of tidal flexure on ice streams and outlet glaciers. Here the theory of Hughes [1977],

Copyright (C) 1981 by the American Geophysical Union. relating vertical displacements of a floating glacier to bending stress and strain at the grounding line, is applied to field measurements made at Jakobshavns Glacier. The extent of cracking (due to flexure) along the grounding line parallel to the north fjord wall is calculated by finding the effective thickness which results in closest agreement between measured displacements of the glacier and vertical displacements as predicted by flexure theory.

\section{SURVEY Results}

The velocity vectors of 10 ice seracs, the approximate position of the calving front, and the north wall of Jakobshavns Fjord are shown in Figure 2; velocities are tabulated in Table 1. Triangulation from the two baselines shown on the north fjord wall was used to fix the positions of these seracs. The seracs were marked with dye dropped from a helicopter, because foot travel on the chaotic glacier surface is not feasible.

Figure 2 shows that the velocity profile along the A-E transect of seracs, and also along the $1-4$ transect, was nearly constant between the centerline of prominent seracs (dotted line in Figure 2), and points close to the north fjord wall such as $B$ and 2. Velocity then decreased abruptly, from $18.2 \mathrm{~m} \mathrm{~d}^{-1}$ for $B$ to $4.7 \mathrm{~m} \mathrm{~d}^{-1}$ for $A$ and from $18.8 \mathrm{~m} \mathrm{~d}^{-1}$ for 2 to $2.3 \mathrm{~m} \mathrm{~d}^{-1}$ for 1 . (This abrupt decrease in ice velocity near the north fjord wall, and also near the grounding line along the south side of the fjord, can be seen graphically in the air photographs of Carbonnell and Bauer [1968].)

Figures 3 and 4 show the vertical movements versus time of individual seracs along the A-E and 1-4 transects, respectively. The frequency of observations was not high enough to determine whether all targets reached maximum and minimum elevations at precisely identical times, but the general agreement of the curves and the timing of the displacement cycles shows that the glacier moves vertically in response to tidal oscillations. A regression formula was used to calculate 


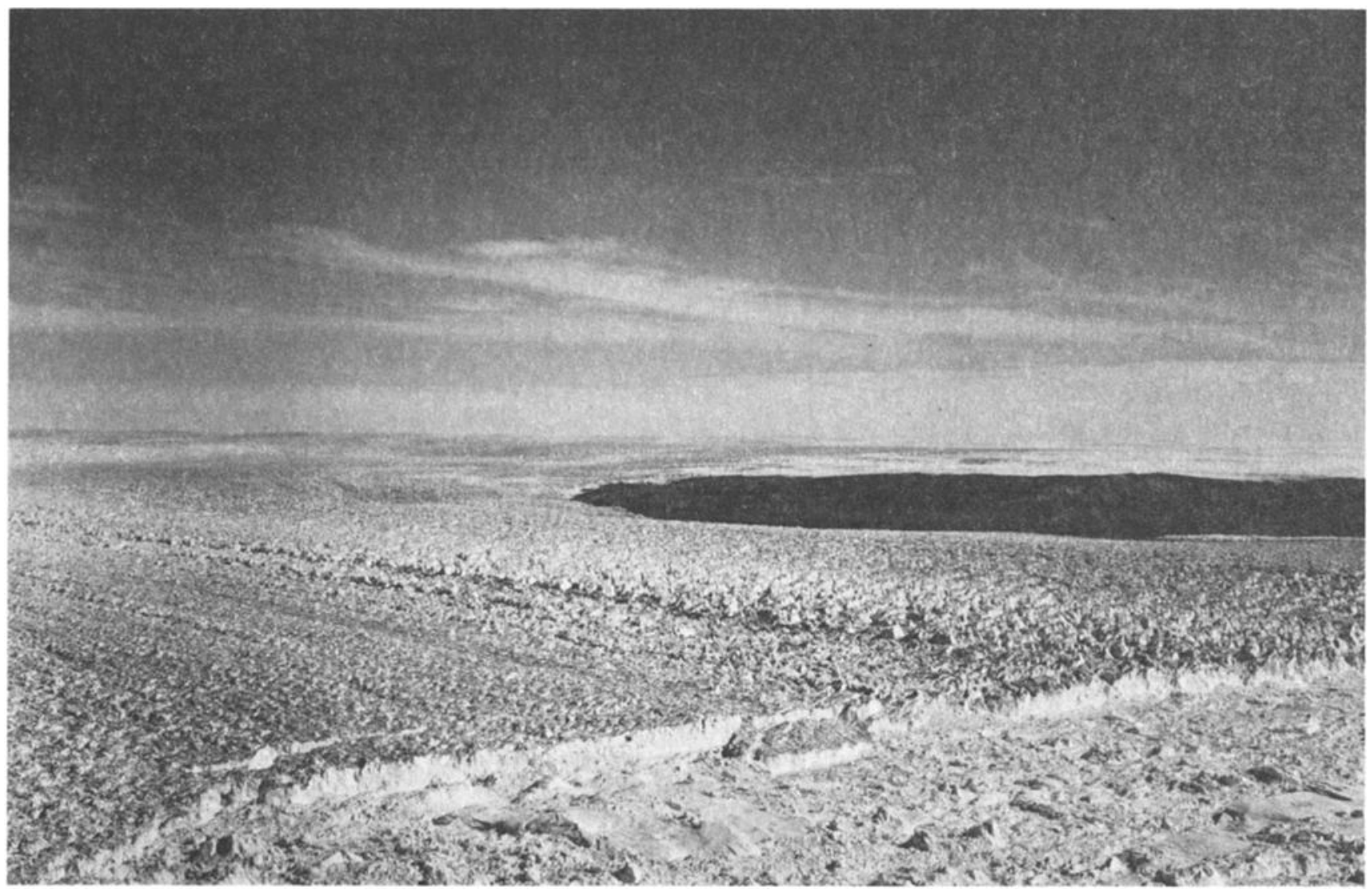

Fig. 1. Jakobshavns Glacier from NW. About $6 \mathrm{~km}$ of the south fjord wall is visible at right. The ice cliff is about $70 \mathrm{~m}$ high; water in right foreground is covered by floating brash ice and small icebergs. The glacier is afloat for about $8 \mathrm{~km}$. Survey targets $E$ and 4 in Figure 2 were located on the prominent centerline row of ice pinnacles. Other survey targets were north (left) of the centerline.

the uncertainty of the elevation measurements; error limits represent uncertainty due to observation error.

Changes in the elevations of the seracs rather than absolute elevations were required for tidal flexure analysis, so approximate refraction corrections were not attempted. Significant errors in vertical angle measurements would have been introduced if refraction varied with changes in cloud cover and sun elevation, however, so a marker was placed on the south side of the glacier and sighted during varying weather conditions. Refraction appeared to be consistent throughout the survey. A high ablation rate would also have increased the uncertainty of elevation measurements if the glacier were grounded, but the effect was largely canceled by flotation. Ablation near the margin was found to average $\sim 0.1 \mathrm{~m} / \mathrm{d}$. If the entire glacier surface were lowered by this amount in 24 hours, flotation would raise the glacier by $\sim 0.09 \mathrm{~m}$. The resultant net lowering of $0.01 \mathrm{~m} / \mathrm{d}$, or $2.5 \times 10^{-3} \mathrm{~m}$ in 6 hours, is insignificant compared to the tide range in Jakobshavns Fjord. (Basal melt rates were unknown.)

The small, irregular vertical movements of targets $A$ and 1 (Figures 3 and 4) generally do not correlate with the tidal movements shown by other targets along the A-E and 1-4 transects. Seracs $A$ and 1 thus appear to have been grounded.

\section{REPRESENTATION OF GLACIER}

An elastic-viscoplastic tidal flexure analysis was applied to the north grounding line of Jakobshavns by approximating the glacier as shown in Figure 5. The following assumptions were made. (1) Measured vertical displacements of the glacier did not reflect bending of its total 750-m thickness (estimated by Carbonnell and Bauer [1968]) near the calving front because of probable deep cracking parallel to the fjord wall along the side grounding line. Cracks may extend downward from the surface to significant depth, but the deepest cracks may extend upward from the glacier's bottom surface and be held open by the hydrostatic pressure of seawater. (2) Tidal bending of the glacier can be correlated with an effective thickness of ice, which acts as an elastic and viscoplastic continuum. The effective thickness can be considered to be the sound-ice thickness between surface and basal cracks at the side grounding line. The sound-ice thickness probably is not constant with increasing distance toward the glacier centerline, but the fiber stress induced by bending ( $\sigma_{x}$ in Figure 6 ) attains a sharp maximum at the side grounding line. Thus the bending behavior of the glacier is essentially controlled by its effective thickness there. (3) The grounding zone is narrow enough to be treated as a line because of the steepness of the fjord wall. Our vertical displacement data imply that the grounding line can be approximated as a clamped boundary (not a hinged or free boundary).

\section{Flexure Within the Marginal Shear Zone}

If ice grains within the marginal shear zone have recrystallized such that basal planes are oriented for easy glide parallel to the fjord wall, those same grains must also be oriented favorably for shear in the vertical direction. The yield stress 


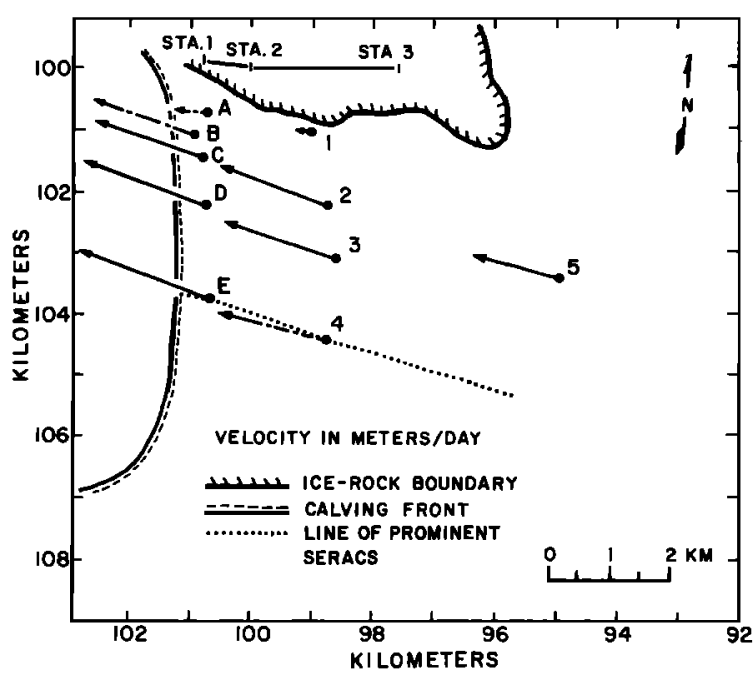

Fig. 2. Locations and velocities of survey targets. The length of each vector is proportional to the velocity of the serac at its tail. Baselines are shown on north fjord wall at upper left. Survey targets that were reliably measured from two stations are represented by solid vectors. Targets with initial positions fixed by observations from two stations, but with velocities determined from the subsequent rate of change of angle from one station, have vectors consisting of alternating long and short dashes. The directions of motion of these targets were estimated from the context of other targets that were more reliably measured and from the direction of a prominent row of seracs (dotted line) which appeared to represent a flow line.

for ice crystals during basal glide is less by about a factor of 10 than for nonbasal glide [Higashi et al., 1968], so it is conceivable that the stress imposed by tidal flexure causes ice basal planes to slide parallel to one another in the vertical direction. Almost all deformation might then be in the form of basal glide within the marginal shear zone. Survey targets from $B$ to the glacier centerline (along the A-E transect) could then be expected to rise and fall by the same amount, if the yield stress was attained at all sections simultaneously.

Figures 3 and 4 show, however, a trend toward decreasing vertical displacement of seracs as the north fjord wall is approached from the glacier centerline. This indicates that fiber stress parallel to the glacier surface ( $\sigma_{x}$ in Figure 6 ) exerts dominan't control during tidal flexure and that basal glide resulting from vertical shear ( $\sigma_{z x}$ in Figure 6 ) is not large. If ice crystal basal planes are in fact oriented for easy glide parallel to the fjord wall, as suggested by the velocity distribution in Figure 2, $\sigma_{x}$ is exerted in a hard glide direction. The soft ice zone for horizontal (or vertical) shear is thus a hard glide zone for tidal flexure. Hard glide leads to strain hardening. We therefore use a strain hardening constitutive relationship.

\section{CONSTITUTIVE Relationship}

The 6-hour intervals between tide changes are short in comparison to the time periods during which most glacier deformations occur, and tidal oscillations cause continuing reversal of the stress field. Thus the flow law of ice [Glen, 1955], which presupposes steady state creep, may not be appropriate for analyses of tidal flexure.

With strain hardening the flow curve of many metals in the region of uniform plastic deformation, during tests conducted at constant strain rate and temperature, can be expressed by a simple power curve relation of the form [Dieter, 1976, p. 340]

$$
\pm \varepsilon= \pm\left|\sigma / \sigma^{*}\right|^{c}
$$

where $\sigma$ is the applied longitudinal stress, $\varepsilon$ is the resulting strain, $c$ is the reciprocal strain hardening exponent, and $\sigma^{*}$ is a strain rate dependent strength coefficient.

During viscoplastic yielding tests on ice single crystals pulled in uniaxial tension at constant strain rate and temperature, Higashi et al., [1968] found that at the yield stress $\sigma=$ $\sigma_{0}$,

$$
\sigma_{0}{ }^{d}=B_{0}|\dot{\varepsilon}| \exp (Q / R T)
$$

where $B_{0}$ is a hardness parameter, $d$ is a yielding parameter, $Q$ is the activation energy of self-diffusion, $R$ is the ideal gas constant, $T$ is the absolute temperature, and $\dot{\varepsilon}$ is the strain rate. For prismatic (hard) glide, $d=6.5$ and $Q=69.1 \mathrm{~kJ} \mathrm{~mole}^{-1}$. Equation (2) implies that

$\sigma^{*}=\left[B_{0}|\dot{\varepsilon}| \exp (Q / R T)\right]^{1 / d} \varepsilon_{0}^{-1 / c}=B^{*}|\dot{\varepsilon}|^{1 / d} \exp (Q / d R T)$

where $\varepsilon_{0}$ is the strain corresponding to yield stress $\sigma_{0}$ and $B^{*}=$ $B_{0}^{1 / d} \varepsilon_{0}{ }^{-1 / c}$.

Hughes [1977] showed that a best fit to the Higashi data is obtained with $c \sim 2$ in (1), an empirical value of $6.32 \mathrm{MN} \mathrm{m}^{-2}$ $\mathbf{s}^{1 / d}$ for $B^{*}$, and that for sufficiently small crystal size, singlecrystal yielding data can be used to predict approximate parabolic strain hardening in polycrystalline ice. We assume that parabolic strain hardening is the dominant process during flexure. For tidal flexure, where strain rates are imposed externally by tide changes in the fjord, (1) (with $c=2$ ) is taken to approximate the viscoplastic component of uniaxial strain $\varepsilon_{x}$ caused by fiber stress $\sigma_{x}$ (Figure 6). The elastic component of $\varepsilon_{x}$ is given by (1) with $c=1$, and $\sigma^{*}=\sigma_{e}^{*}=E /\left(1-\mu^{2}\right)$, where $E$ is Young's modulus and $\mu$ is Poisson's ratio. (The analogy between the strain $\varepsilon_{x}$ which occurs in response to fiber stress $\sigma_{x}$ and tests conducted at constant strain rate is an approximation, because at maximum tide, $\varepsilon_{x}$ varies from 0 at the neutral axis of the glacier to maximum at the top (or bottom) surface. Thus during flexure, differing strain rates occur at differing vertical distances from the neutral axis.)

\section{Equations of BENDING}

By balancing forces and moments within the zone of bending, Hughes [1977] has shown that the vertical displacement $z$ of the neutral axis of the glacier, as a function of distance $x$ from the grounding line, is governed by

$$
\frac{d^{4} z}{d x^{4}}=\left[\frac{2+1 / c}{2 \sigma^{*} H^{2+1 / c}}\right]^{c}\left[c(c-1) M^{c-2}\left(\frac{d M}{d x}\right)^{2}+c M^{c-1} \frac{d^{2} M}{d x^{2}}\right]
$$

where $M$ is total moment as shown in Figure 6, $c$ is the reciprocal strain hardening exponent in (1), and $H$ is the distance from the neutral axis to the effective surface as shown in Fig-

TABLE 1. Velocities of Seracs

\begin{tabular}{cc}
\hline Serac & Velocity, $\mathrm{m} \mathrm{d}^{-1}$ \\
\hline E & $22.9 \pm 0.4$ \\
D & $21.4 \pm 0.2$ \\
C & $18.8 \pm 0.1$ \\
B & $18.2 \pm 0.4$ \\
A & $4.7 \pm 0.4$ \\
4 & $18.8 \pm 0.6$ \\
3 & $19.5 \pm 0.2$ \\
2 & $18.8 \pm 0.9$ \\
1 & $2.3 \pm 0.1$ \\
5 & $15.3 \pm 0.7$ \\
\hline
\end{tabular}



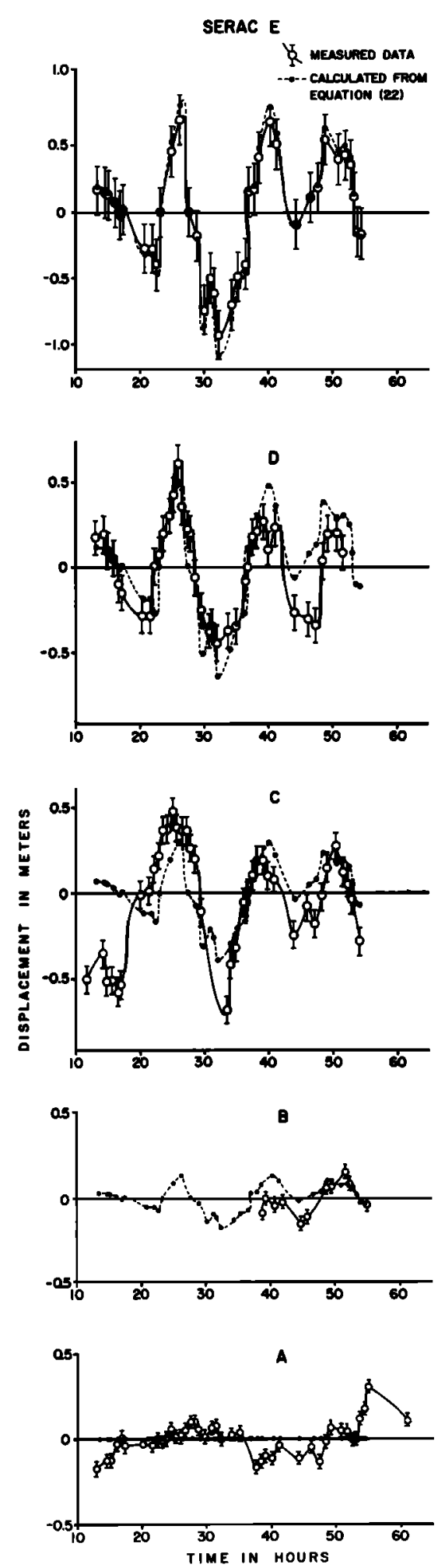

Fig. 3. Vertical movements versus time for targets E, D, C, B, and A. The zero-elevation datum in each diagram is the mean elevation of the serac during the time of the survey. Time zero is midnight at the beginning of July 18 . Solid circles and dashed curves represent displacements calculated from equation (22).

ure 5. The equation of the elastic component of displacement $z_{e}$ is obtained by setting $c=1$. Then

$$
\frac{d^{4} z_{e}}{d x^{4}}=\left[\frac{3}{2 \sigma_{e}^{*} H^{3}}\right] \frac{d M}{d x^{2}}
$$

The second derivative of moment is related to the difference between the free rise of the tide $z_{f}$ and the elastic component of displacement by

$$
\frac{d^{2} M}{d x^{2}}=\rho_{w} g\left(z_{f}-z_{e}\right)
$$

where $\rho_{w}$ is the density of seawater and $g$ is the acceleration due to gravity. Substitution of (6) in (5) yields

$$
\frac{d^{4} z_{e}}{d x^{4}}=\left[\frac{3 \rho_{m} g}{2 \sigma_{e}^{*} H^{3}}\right]\left(z_{f}-z_{e}\right)
$$

Equation (7) is the equation applied by Robin [1958] to the problem of bending of ice shelves at their junctions with the Antarctic inland ice and by Holdsworth [1969] in his elastic analysis of tidal bending of floating ice tongues. The general solution is

$$
\begin{aligned}
\left(z_{f}-z_{e}\right)=\left(C_{1} \cos \lambda x+C_{2} \sin \lambda x\right) \exp (\lambda x) \\
+\left(C_{3} \cos \lambda x+C_{4} \sin \lambda x\right) \exp (-\lambda x)
\end{aligned}
$$
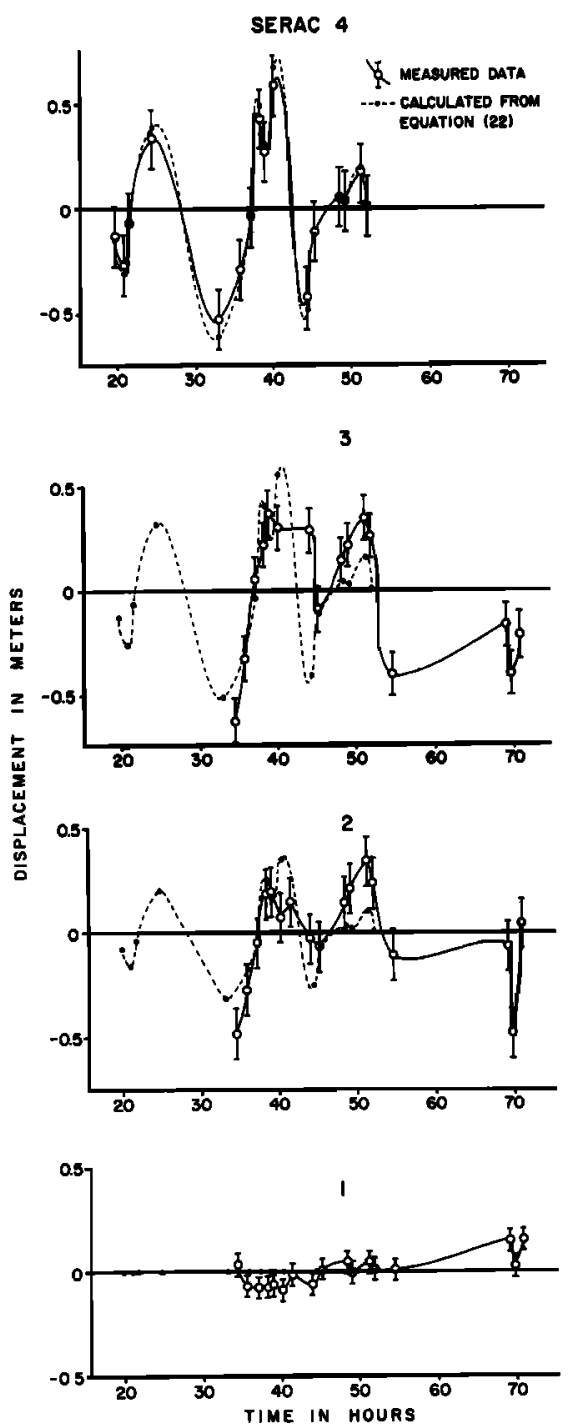

Fig. 4. Vertical movements versus time for targets 4, 3, 2, and 1 (data gathered by R. H. Thomas). Solid circles and dashed curves represent displacements calculated from equation (22). 

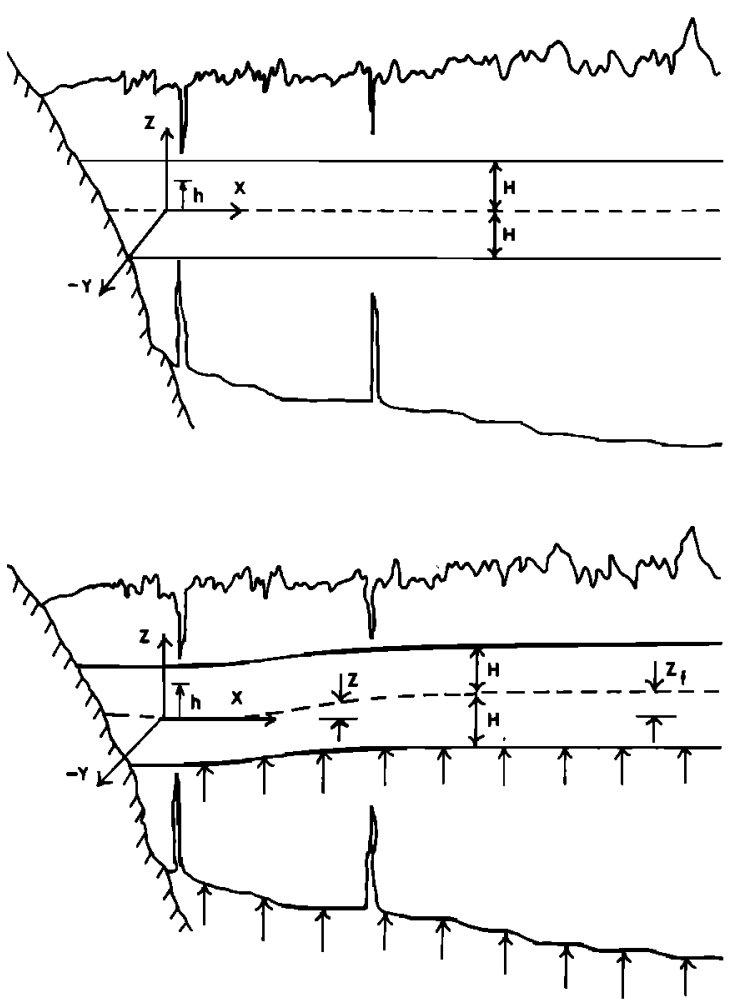

Fig. 5. Sketch of glacier cross section along A-E (or 1-4) transect. The north fjord wall is at left; ice is flowing out of the plane of the page. Survey targets are assumed to move vertically in accordance with the bending properties of an unknown effective thickness $2 \mathrm{H}$. At sufficiently large distance from the side grounding line the rise of the glacier is assumed equal to $z_{f}$, the free rise of the tide.

where

$$
\lambda=\left[3 \rho_{w} g / 8 \sigma_{e}^{*} H^{3}\right]^{1 / 4}
$$

is an elastic damping factor and $C_{1}, C_{2}, C_{3}$, and $C_{4}$ are constants to be evaluated from the boundary conditions. If bending were purely elastic, the boundary conditions would be applied directly to (8). These are (1) unbounded growth of the solution cannot occur, so $C_{1}=C_{2}=0$, and (2) at $x=0, z=$ $d z / d x=0$, so $C_{3}=C_{4}=z_{f}$. Thus the displacement solution for pure elastic bending is

$$
z_{e}=z_{f}[1-(\cos \lambda x+\sin \lambda x) \exp (-\lambda x)]
$$

The equation for the viscoplastic component of displacement $z_{\nu}$ is obtained by setting $c=2$ in (4). Then

$$
\frac{d^{4} z_{v}}{d x^{4}}=\left[\frac{5}{4 \sigma_{v}^{*} H^{3 / 2}}\right]^{2}\left[2\left(\frac{d M}{d x}\right)^{2}+2 M\left(\frac{d^{2} M}{d x^{2}}\right)\right]
$$

where $\sigma_{\nu}{ }^{*}$ is a viscoplastic strength coefficient. Equation (11) is awkward to solve, however, because of nonlinearity.

Here the approach of Hughes [1977] is used to obtain an approximate linear equation for the viscoplastic component of displacement. The 3-hour interval between neutral and maximum tides is assumed to be sufficiently short to consider the viscoplastic component of strain $\varepsilon_{x}$ (Figure 6) to be determined approximately by the initial stress distribution established by elastic deformation.

Using $\sigma_{x}=\left(\sigma_{x}\right)_{H}$ to denote fiber stress at distance $H$ above (or below) the neutral axis and (1) with $c=1$ for elastic flexure, $\left(\sigma_{x}\right)_{H}=\left(\sigma_{e}^{*}\right)\left(\varepsilon_{x}\right)_{H}$. Fiber strain $\left(\varepsilon_{x}\right)_{H}$ is related to the average radius of curvature $r_{x}$ of the neutral axis (Figure 6 ) by
$\left(\varepsilon_{x}\right)_{H}=H / r_{x}\left[\right.$ Popov, 1952, pp. 269-271], so $\left(\sigma_{x}\right)_{H}=\left(\sigma_{e}^{*}\right)(H /$ $\left.r_{x}\right)$. For deflections that are small in comparison to the effective thickness of the glacier (i.e., $\left.(d z / d x)^{2} \ll 1\right)$, curvature $1 / r_{x}$ $\sim d z_{e} / d x^{2}$, so

$$
\left(\sigma_{x}\right)_{H}=\sigma_{e}^{*} H d^{2} z_{e} / d x^{2}
$$

where $z_{e}$ is given by (10). Differentiating (10) twice and substituting in (12) yields

$$
\left(\sigma_{x}\right)_{H}=2 \sigma_{e}^{*} H \lambda^{2} z_{f}(\cos \lambda x-\sin \lambda x) \exp (-\lambda x)
$$

where $\lambda$ is given by (9) and $\sigma_{e}^{*}=E /\left(1-\mu^{2}\right)$. Equation (13) is the stress solution applied by Robin [1958] to floating ice shelves and by Holdsworth [1969] to floating ice tongues.

Since the total strain $\varepsilon_{x}$ has both elastic and viscoplastic components and since elastic strain is generally observed to continue increasing linearly with stress even after viscoplastic strain has become dominant,

$$
\left|\varepsilon_{x}\right|=\left|\varepsilon_{e}\right|+\left|\varepsilon_{v}\right|=\left|\sigma_{x} / \sigma_{e}^{*}\right|+\left|\sigma_{x} / \sigma_{v}^{*}\right|^{2}
$$

Strain $\varepsilon_{x}$ is taken to be the average strain within the ice column caused by tide rise $z_{f}$, and $\sigma_{v}^{*}$ is the average strength coefficient corresponding to $\varepsilon_{x}$ and $\dot{\varepsilon}_{x}$. Viscoplastic strain $\varepsilon_{v}$, at distance $H$ from the neutral axis, is obtained by substituting (13) in the $\left|\sigma_{x} / \sigma_{v}^{*}\right|^{2}$ term in (14):

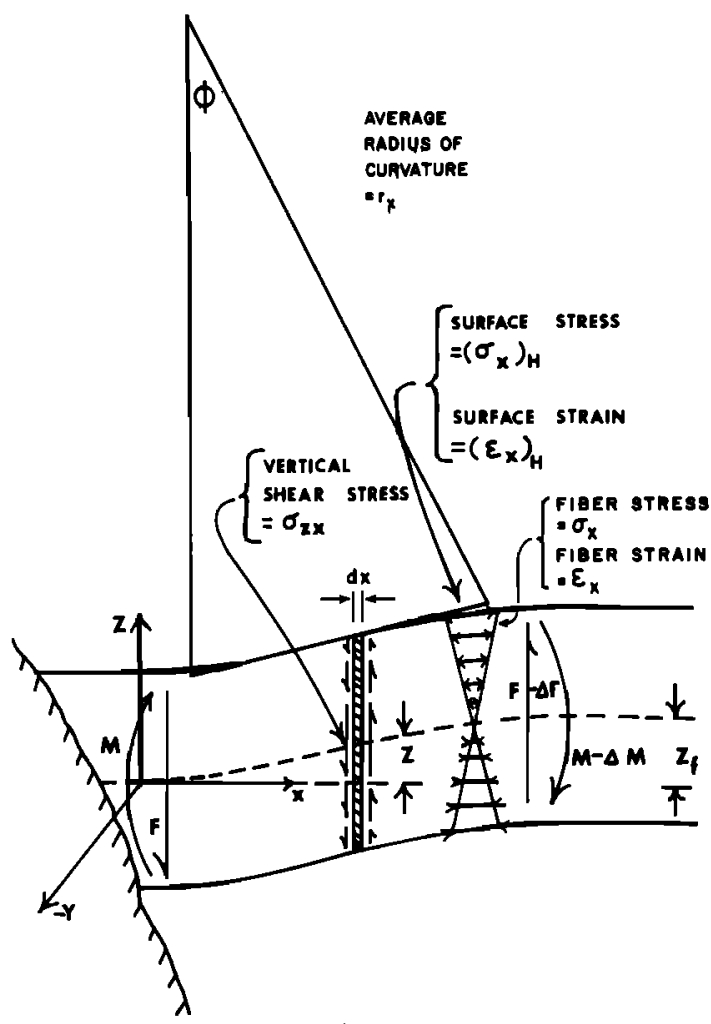

Fig. 6. Stress, strain, and moment imposed within the zone of bending by a rise from neutral tide of $z_{f}$. Fiber stress $\sigma_{x}$ is caused by moment induced by resultant upward force within the zone of bending, acting on a moment arm equal to its distance from the side grounding line. Shear stress $\sigma_{z x}$ resists net upward force and is substantially less than $\sigma_{x}$. Fiber stress $\sigma_{x}$ and strain $\varepsilon_{x}$ are assumed to increase linearly from 0 at the neutral axis to maximum at the top (and bottom) effective surfaces, for elastic flexure. The origin of the coordinate system is above the side grounding line. 


$$
\left(\varepsilon_{v}\right)_{H}=\left[\frac{3 \rho_{w} g z_{f}^{2} E}{2 H\left(1-\mu^{2}\right)\left(\sigma_{v}^{*}\right)^{2}}\right](\cos \lambda x-\sin \lambda x)^{2} \exp (-2 \lambda x)
$$

Since $\left(\varepsilon_{x}\right)_{H}=H / r_{x}$ and $1 / r_{x} \sim d^{2} z_{v} / d x^{2}$,

$$
\begin{aligned}
\frac{d^{2} Z_{v}}{d x^{2}} & =\frac{\left(\varepsilon_{v}\right)_{H}}{H} \\
& =\left[\frac{3 \rho_{w} g z_{f}^{2} E}{2 H^{2}\left(1-\mu^{2}\right)\left(\sigma_{v}^{*}\right)^{2}}\right](\cos \lambda x-\sin \lambda x)^{2} \exp (-2 \lambda x)
\end{aligned}
$$

is an approximate linear equation for the viscoplastic component of displacement. The general solution is

$$
z_{v}=\left(K / 8 \lambda^{2}\right) \exp (-2 \lambda x)(2-\cos 2 \lambda x)+C_{5} x+C_{6}
$$

where

$$
K=\frac{3 \rho_{w} g z_{f}^{2} E}{2 H^{2}\left(1-\mu^{2}\right)\left(\sigma_{v}^{*}\right)^{2}}
$$

and $C_{5}$ and $C_{6}$ are constants of integration. Total vertical displacement is the sum of the elastic and viscoplastic components. Addition of (8) and (17) yields

$$
\begin{aligned}
z= & z_{e}+z_{v}=z_{f}-\left(C_{1} \cos \lambda x+C_{2} \sin \lambda x\right) \exp (\lambda x) \\
& -\left(C_{3} \cos \lambda x+C_{4} \sin \lambda x\right) \exp (-\lambda x) \\
& +\left(K / 8 \lambda^{2}\right) \exp (-2 \lambda x)(2-\cos 2 \lambda x)+C_{5} x+C_{6}
\end{aligned}
$$

Since unbounded growth cannot occur, $C_{1}=C_{2}=C_{5}=0$. From $z \rightarrow z_{f}$ as $x \rightarrow \infty, C_{6}=0$. From $z=0$ at $x=0, C_{3}=z_{f}+$ $\left(K / 8 \lambda^{2}\right)$. From $d z / d x=0$ at $x=0, C_{4}=z_{f}-\left(K / 8 \lambda^{2}\right)$. The solution for elastic and viscoplastic displacement is thus

$$
\begin{aligned}
z=z_{f}-\left[\left(z_{f}+\frac{K}{8 \lambda^{2}}\right)\right. & \left.\cos \lambda x+\left(z_{f}-\frac{K}{8 \lambda^{2}}\right) \sin \lambda x\right] \exp (-\lambda x) \\
& +\frac{K}{8 \lambda^{2}} \exp (-2 \lambda x)(2-\cos 2 \lambda x)
\end{aligned}
$$

\section{Determination of EFFECTIVE ThickNess}

Effective thickness was first calculated by assuming that vertical displacements of the glacier were due entirely to elastic bending. Values were assigned to the known terms in (9), and $H$ was varied until $\lambda$ gave the best fit between (10) and measured displacements of the seracs along the A-E transect and also along the 1-4 transect (Figure 2).

Using $E=8.8 \times 10^{9} \mathrm{~N} / \mathrm{m}^{2}, \mu=0.3, \rho_{w}=1020 \mathrm{~kg} / \mathrm{m}^{3}, g=$ $9.8 \mathrm{~m} / \mathrm{s}^{2}$, and half of the $0.79-\mathrm{m}$ drop of serac E during the tide drop from 38.8 to 44.3 hours (Figure 3 ) for $z_{f}$, effective thickness $2 H=110 \mathrm{~m}$ resulted in a best fit along the A-E transect. Along the 1-4 transect, using half of the 1.14-m rise of serac 4 during the tide rise from 34.4 to 39.0 hours (Figure 4) for $z_{f}, 2 H=160 \mathrm{~m}$ resulted in a best fit.

Use of these effective thickness values in (13) yields $\left(\sigma_{x}\right)_{H}=$ $\pm 0.64 \mathrm{MN} / \mathrm{m}^{2}$ at $x=0$ and $\mp 0.13 \mathrm{MN} / \mathrm{m}^{2}$ at $x=1.3 \mathrm{~km}$ from the side grounding line, at maximum tide, along the A-E transect. Along the 1-4 transect, $\left(\sigma_{x}\right)_{H}= \pm 0.77 \mathrm{MN} / \mathrm{m}^{2}$ at $x=$ 0 and $\mp 0.16 \mathrm{MN} / \mathrm{m}^{2}$ at $x=1.7 \mathrm{~km}$ from the side grounding line, at maximum tide. Thus although tidal flexure can be accounted for by pure elastic bending if suitably small values are assumed for effective thickness, the induced fiber stress at the side grounding line, and also at the next stress maximum, is large enough to suggest that viscoplastic strain must also occur.

A second, more realistic estimate of effective thickness was made by matching (20) to the data. Equation (20) contains the viscoplastic strength coefficient $\sigma_{v}{ }^{*}$, which (as is shown by (3)) is a function of strain rate as well as temperature. Thus $\sigma_{v}{ }^{*}$ must be evaluated for the conditions prevailing during particular stages of the deformation. This difficulty was approached by first finding limiting values for $\sigma_{v}{ }^{*}$ through calculation of the range of average longitudinal strain rates $\dot{\varepsilon}_{x}$ that might occur above the grounding line during the time from neutral to maximum tide. Equation (3) was then used to determine a corresponding, more restricted range for $\sigma_{v}{ }^{*}$. (The range of $\sigma_{v}{ }^{*}$ is more restricted than the range of $\dot{\varepsilon}_{x}$, because $\dot{\varepsilon}_{x}$ is raised to the $1 / d=1 / 6.5$ power in (3).)

For a minimum value of $\sigma_{v}^{*}$ the glacier was assumed to be cracked such that effective thickness $2 H=110 \mathrm{~m}$, as calculated above for pure elastic bending. Strain $\left(\varepsilon_{x}\right)_{H}$ at distance $H$ from the neutral axis is $\left(\sigma_{x}\right)_{H} / \sigma_{e}{ }^{*}$, where $\left(\sigma_{x}\right)_{H}$ is given by (13). At $x=0$ this becomes

$$
\left(\varepsilon_{x}\right)_{H}=\left(\sigma_{x}\right)_{H} / \sigma_{e}^{*}=2 H \lambda^{2} z_{f}
$$

Taking average strain $\bar{\varepsilon}_{x} \sim 1 / 2\left(\varepsilon_{x}\right)_{H}$, time from neutral to maximum tide $\sim 3$ hours, and $z_{f} \sim 0.5 \mathrm{~m}$ gives $\left(\varepsilon_{x}\right)_{H}=8.39 \times 10^{-5}$, $\bar{\varepsilon}_{x}=4.19 \times 10^{-5}, \overline{\dot{\varepsilon}}_{x}=3.88 \times 10^{-9} \mathrm{~s}^{-1}$. For $T \sim 0^{\circ} \mathrm{C}=273^{\circ} \mathrm{K}$, (3) yields $\sigma^{*}=\left(\sigma_{v}^{*}\right)_{\min }=34.6 \mathrm{MN} / \mathrm{m}^{2}$.

For a maximum value of $\sigma_{v}{ }^{*}$, effective thickness $2 H=700$ $m$ was assumed; that is, the glacier was assumed to be essentially uncracked along the side hinge line. (This assumption was made because obvious flexure cracks could not be distinguished parallel to the north fjord wall.) The glacier was also assumed to bend with the same radius of curvature, which is prescribed by the survey data. By hypothesis, strain $\varepsilon_{x}$ increases linearly from 0 at the neutral axis to maximum at $h=$ $\pm H$, where $h$ is distance from the neutral axis, that is, $\varepsilon_{x}=(h)$ $H\left(\varepsilon_{x}\right)_{H}$. From the preceding paragraph, $\varepsilon_{x}=8.39 \times 10^{-5}$ for $H=55 \mathrm{~m}$, so $\left(\varepsilon_{x}\right)_{H}=5.34 \times 10^{-4}$ at $H=350 \mathrm{~m}$, and $\bar{\varepsilon}_{x}=2.67$ $\times 10^{-4}$. Again taking time to be 3 hours and $T \sim 273^{\circ} \mathrm{K}, \overline{\dot{\varepsilon}}_{x}=$ $2.47 \times 10^{-8} \mathrm{~s}^{-1}$, and, from (3), $\sigma^{*}=\left(\sigma_{v}{ }^{*}\right)_{\max }=46.0 \mathrm{MN} / \mathrm{m}^{2}$. Thus $34.0<\sigma_{v}{ }^{*}<46.0 \mathrm{MN} / \mathrm{m}^{2}$ along the A-E transect. A similar calculation resulted in $32.0<\sigma_{v}{ }^{*}<41.0 \mathrm{MN} / \mathrm{m}^{2}$ along the 1-4 transect. Note that the range of $\overline{\dot{\varepsilon}}_{x}$ for the A-E transect is $3,88 \times 10^{-9} \mathrm{~s}^{-1}<\bar{\varepsilon}_{x}<2.47 \times 10^{-8} \mathrm{~s}^{-1}$, so a variation of average strain rate above the grounding line of about $\pm 73 \%$ corresponds to a variation in $\sigma_{v}{ }^{*}$ of about $\pm 15 \%$.

Combinations of effective thickness $2 H$ and $\sigma_{v}{ }^{*}$ which resulted in an optimum fit of (20) to the data were found by trial and error; that is, predicted displacements at maximum tide were calculated for all survey targets along both transects, and the results were compared to measured displacements. Combinations of $2 H$ and $\sigma_{v}^{*}$ which resulted in agreement to within a specified tolerance were selected. (For any $\sigma_{v}{ }^{*}$ within the range $34.0<\sigma_{v}{ }^{*}<46.0 \mathrm{MN} / \mathrm{m}^{2}$, for instance, a value of effective thickness within the range $170<2 H<230 \mathrm{~m}$ could be found which resulted in a good fit to the data along the A-E transect, when the tide drop between 38.8 and 44.3 hours was used.)

Given combinations of effective thickness and $\sigma_{v}^{*}$ which satisfied the survey data, iteration was used to converge to the unique combination that was also consistent with (3) at the grounding line. This was done by recalculating $\sigma_{v}{ }^{*}$ from (13), (14), and (3) in the manner described above for calculation of 
TABLE 2. Comparison Between Measured Displacements and Displacements Calculated From Equation (20), at Different Times

\begin{tabular}{|c|c|c|c|c|c|c|c|}
\hline \multirow{3}{*}{$\begin{array}{l}\text { Survey } \\
\text { Target }\end{array}$} & \multirow{3}{*}{$\begin{array}{c}\text { Distance } \\
\text { From Side } \\
\text { Grounding } \\
\text { Line, km }\end{array}$} & \multicolumn{6}{|c|}{ Vertical Displacements, Elastic Plus Viscoplastic Flexure, m } \\
\hline & & \multicolumn{2}{|c|}{ Time $=38.8-44.3$ Hours } & \multicolumn{2}{|c|}{ Time $=44.3-48.7$ Hours } & \multicolumn{2}{|c|}{ Time $=48.7-54.4$ Hours } \\
\hline & & Measured & Calculated & Measured & Calculated & Measured & Calculated \\
\hline \multirow{7}{*}{$\begin{array}{l}\text { A } \\
\text { B } \\
\mathbf{C} \\
\mathbf{D} \\
\mathbf{E}\end{array}$} & 0.0 & & 0.0 & & 0.0 & & 0.0 \\
\hline & 0.411 & $0.07 \pm 0.04$ & 0.08 & $0.16 \pm 0.04$ & 0.13 & $0.09 \pm 0.04$ & 0.10 \\
\hline & 0.716 & $0.22 \pm 0.08$ & 0.17 & $0.22 \pm 0.08$ & 0.24 & $0.26 \pm 0.08$ & 0.20 \\
\hline & 1.505 & $0.35 \pm 0.13$ & 0.35 & $0.35 \pm 0.13$ & 0.35 & & 0.36 \\
\hline & 3.049 & $0.39 \pm 0.19$ & 0.43 & $0.32 \pm 0.19$ & 0.33 & $0.36 \pm 0.19$ & 0.39 \\
\hline & & \multicolumn{2}{|c|}{ Time $=34.4-39.0$ Hours } & \multicolumn{2}{|c|}{ Time $=39.0-44.9$ Hours } & \multicolumn{2}{|c|}{ Time $=44.9-52.2$ Hours } \\
\hline & & Measured & Calculated & Measured & Calculated & Measured & Calculated \\
\hline 1 & 0.0 & & 0.0 & & 0.0 & & 0.0 \\
\hline 2 & 1.224 & $0.33 \pm 0.12$ & 0.31 & $0.13 \pm 0.12$ & 0.18 & $0.20 \pm 0.12$ & 0.17 \\
\hline 3 & 2.094 & $0.49 \pm 0.10$ & 0.46 & $0.38 \pm 0.10$ & 0.31 & $0.22 \pm 0.10$ & 0.26 \\
\hline 4 & 3.429 & $0.48 \pm 0.14$ & 0.53 & $0.42 \pm 0.14$ & 0.42 & $0.29 \pm 0.14$ & 0.31 \\
\hline
\end{tabular}

the extreme values of $\sigma_{u}{ }^{*}$. The recalculated value was substituted back in (20), and the effective thickness which resulted in a best fit to the survey data was again found. Three to five such iterations resulted in convergence. This procedure was carried out for each tide rise (or fall) for which data were available for all survey targets along the A-E transect and also along the 1-4 transect. The results are summarized in Tables 2 and 3. Figures 7 and 8 compare deflection curves calculated from (20) to measured displacements, using the effective thickness values shown in Table 3.

The average effective thickness for the A-E transect is 160 $\pm 48 \mathrm{~m}$ and for the $1-4$ transect is $316 \pm 74 \mathrm{~m}$. Error limits are the mean difference between the average effective thickness and the extreme values for each transect, as shown in Table 3.

\section{COMPARISON OF BENDING EQUATION to All Data PoINTs}

Equation (20) can be compared directly to the individual flexure data points shown in Figures 3 and 4 if the movements of seracs $E$ and 4 are used to define successive departures from neutral tide $\left(z_{f}\right)$ for the A-E and $1-4$ transects, respectively. (The vertical movements of seracs along the $1-4$ transect may have been inhibited somewhat by pinning at the rear grounding line, since displacements were generally less than those along the A-E transect. The effect of this average reduction of displacement was eliminated by using the movements of serac 4 , instead of serac $E$, to define successive departures from neutral tide. Relative bending along the remainder of the 1-4 transect was then interpreted in terms of effective thickness at the grounding line.)

Equations (13) and (14) were used to compute average strain above the grounding line for each value of $z_{f}$, starting with an assumed value of $\sigma_{v}{ }^{*}$ and using a particular value of effective thickness as computed for one period of tide rise or fall, as shown in Table 3. The iterative procedure described above was then used to converge to the value of $\sigma_{v}{ }^{*}$ appropriate for $z_{f}$ and the corresponding average strain rate above the grounding line. When this was done, the term $K / 8 \lambda^{2}$ in (20) was found to be similar in magnitude to $z_{f}$. For a majority of serac $E$ data points, $0.5 z_{f} \leq K / 8 \lambda^{2} \leq 1.01 z_{f}$. The $\cos \lambda x$ term in (20) thus dominates the $\sin \lambda x$ term, since $\left[z_{f}+\left(K / 8 \lambda^{2}\right)\right]>\left[z_{f}\right.$
- $\left(K / 8 \lambda^{2}\right)$ ] by a factor of 3-20. The deflection curve can thus be approximated by setting $K / 8 \lambda^{2} \sim z_{f}$ in (20), which yields

$z \sim z_{f}[1-\exp (-2 \lambda x) \cos 2 \lambda x]$

$$
+2 z_{f}[\exp (-2 \lambda x)-\exp (-\lambda x) \cos \lambda x]
$$

Originally, $K / 8 \lambda^{2}$ was simply assumed to be approximately equal to $z_{f}$ [Lingle, 1978], and effective thickness was found by adjusting $2 H$ to attain a best fit between (22) and the data. This resulted in somewhat greater values of effective thickness than those reported here, that is, $2 \mathrm{H}=270 \mathrm{~m}$ instead of average $2 H=160 \mathrm{~m}$ for the A-E transect and $2 H=370 \mathrm{~m}$ instead of average $2 H=316 \mathrm{~m}$ for the $1-4$ transect. Figure $3 \mathrm{com}$ pares measured displacements and displacements as calculated from (22) for the A-E transect. Figure 4 compares measured and calculated displacements for the 1-4 transect.

The slight mismatch between measured and calculated displacements for $E$ (which was used to define departures from neutral tide; thus calculated and measured displacements should be identical) suggests that this serac was not sufficiently far from the side grounding line to be rising and falling freely with the tide. The discrepancies between measured and calculated displacements increase somewhat with increasing distance from $\mathrm{E}$ toward the side grounding line, but in general, agreement is fair. In particular, note that calculated and measured displacements for serac $B$ are similar in magnitude. If substantial vertical glide along basal planes occurred in re-

TABLE 3. Effective Thicknesses that Resulted in a Best Fit Between Survey Data and Equation (20), at Different Times

\begin{tabular}{cccc} 
Time, Hours & $\begin{array}{c}\text { Strength } \\
\text { Coefficient } \\
\sigma_{v}^{*} \\
\text { MN/m }\end{array}$ & $\begin{array}{c}\text { Effective } \\
\text { Thickness, } \\
\mathrm{m}\end{array}$ & $\begin{array}{c}\text { Average } \\
\text { Effective } \\
\text { Thickness, } \\
\text { m }\end{array}$ \\
\hline \multicolumn{4}{c}{ A-E Transect } \\
$38.8-44.3$ & 39.5 & 210 & \\
$44.3-48.7$ & 39.2 & 114 & $160 \pm 48$ \\
$48.7-54.4$ & 39.8 & 158 & \\
\multicolumn{4}{c}{$1-4$ Transect } \\
$34.4-39.0$ & 41.2 & 264 & \\
$39.0-44.9$ & 37.0 & 412 & $316 \pm 74$ \\
$44.9-52.2$ & 34.8 & 272 & \\
\hline
\end{tabular}




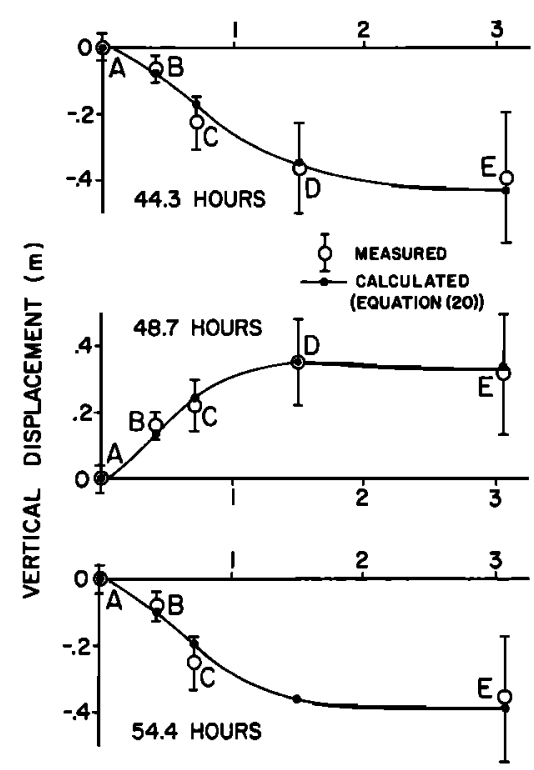

DISTANCE FROM SIDE GROUNDING LINE (km)

Fig. 7. Deflection curves, calculated from equation (20), and measured displacements for the A-E transect.

sponse to shear stress $\sigma_{z x}$ (Figure 6), proportionately more vertical movement would have occurred close to the valley wall; that is, the measured displacements for B would have been greater. This indicates further that the glacier bends in response to tidal flexure and that vertical shear does not play a large role, despite the (apparently) favorable orientation of ice crystals within the marginal shear zone. The calculated displacements for serac $A$ are uniformly 0 , since $A$ was defined to represent the side grounding line.

Figure 4 shows the comparison between (22) and measured displacements along the $1-4$ transect. As in the case of serac $\mathrm{E}$, the mismatch between measured and calculated dis-

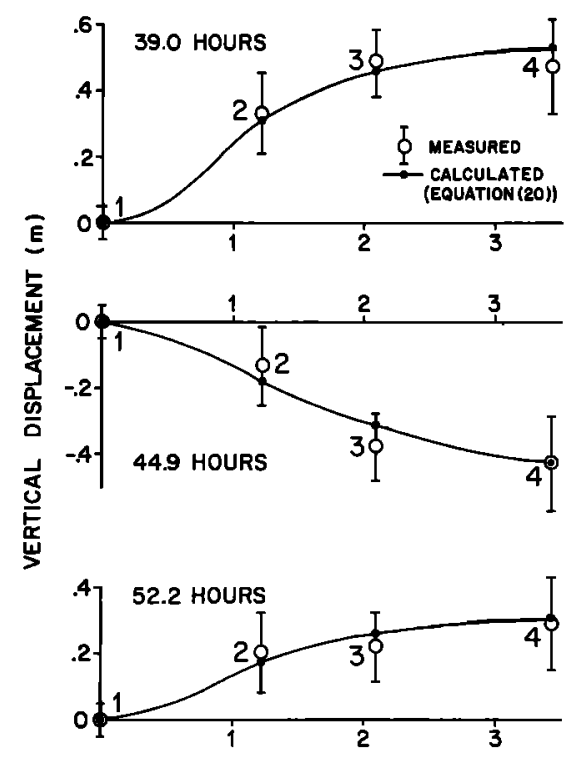

Fig. 8. Deflection curves, calculated from equation (20), and measured displacements for the $1-4$ transect. placements for serac 4 suggests that this serac was not sufficiently far from the side grounding line to be rising and falling freely with the tide (in addition to being inhibited somewhat by the rear grounding line). The calculated displacements for serac 1 are 0 , since serac 1 was defined to represent the side grounding line.

\section{Effective Surface STRess Versus Distance FroM SIDE GROUNDING LINE}

Effective surface stress, as used here, means fiber stress $\sigma_{x}$ (Figure 6) at a distance of plus or minus half the effective thickness from the neutral axis. Table 4 shows the stress maxima at the side grounding line, as calculated from (13), corresponding to the effective thicknesses determined for both the A-E and 1-4 transects. The values of the second stress maxima and their distances from the side grounding line are also shown. The stress maxima become smaller with increasing effective thickness. This is because $\left(\sigma_{x}\right)_{H}$ is inversely proportional to the radius of curvature $r_{x}$ (Figure 6). (See discussion preceding (12).) Equations (13) and (9) show that $\left(\sigma_{x}\right)_{H}$ is also inversely proportional to the square root of effective thickness.

Figure 9 shows $\left(\sigma_{x}\right)_{H}$ as a function of distance from the side grounding line. An effective thickness of $158 \mathrm{~m}$ and $z_{f}=0.36$ $m$ were used for the A-E transect. Maximum stress at the hinge line is $\pm 0.49 \mathrm{MN} / \mathrm{m}^{2}$. The next stress maximum is $\mp 0.1$ $\mathrm{MN} / \mathrm{m}^{2}$; it occurs at (a poorly defined) $1.7 \mathrm{~km}$ toward the glacier centerline. An effective thickness of $264 \mathrm{~m}$ and $z_{f}=0.48$ m were used to plot $\left(\sigma_{x}\right)_{H}$ for the 1-4 transect. Maximum stress is $\pm 0.5 \mathrm{MN} / \mathrm{m}^{2}$ at the hinge line and $\mp 0.1 \mathrm{MN} / \mathrm{m}^{2}$ at $\sim 2.5 \mathrm{~km}$ toward the center of the glacier. The line defining the second stress maximum is not parallel to the north fjord wall, since the glacier thins in the downstream direction.

\section{CONCLUSIONS}

Tidal flexure causes deep basal and surface cracking along the grounding line parallel to the north margin of Jakobshavns Glacier. The glacier bends in accordance with an average effective thickness, or thickness which acts as an elastic and viscoplastic continuum during flexure, of $160 \pm 48 \mathrm{~m}$ ( $\sim 21 \%$ of the estimated $750-\mathrm{m}$ total thickness) $0.6 \mathrm{~km}$ from the calving front and $316 \pm 74 \mathrm{~m}$ ( $\sim 40 \%$ of the estimated $800-\mathrm{m}$ total) $2.6 \mathrm{~km}$ upglacier from the calving front. Ice which has begun floating in the fjord takes about 1 year to reach the cal-

TABLE 4. Effective Surface Stress Maxima Versus Effective Thickness and Distance From Side Grounding Line

\begin{tabular}{ccccc}
\hline $\begin{array}{c}\text { Effective } \\
\text { Thickness, } \\
\mathrm{m}\end{array}$ & $\begin{array}{c}\left(\sigma_{x}\right)_{H} \text { at } \\
\text { Side } \\
\text { Grounding } \\
\text { Line, } \\
\pm, \mathrm{MN} / \mathrm{m}^{2}\end{array}$ & $\begin{array}{c}\left(\sigma_{x}\right)_{H} \text { at } \\
\text { Second } \\
\text { Stress } \\
\text { Maximum, } \\
\mp, \mathrm{MN} / \mathrm{m}^{2}\end{array}$ & $\begin{array}{c}\text { Distance } \\
\text { From Side } \\
\text { Grounding } \\
\text { Line, } \\
\mathbf{k m}\end{array}$ & $\begin{array}{c}\text { Change } \\
\text { From } \\
\text { Neutral } \\
\text { Tide, } \\
z_{f} \mathbf{m}\end{array}$ \\
\hline \multirow{5}{*}{$\begin{array}{c}A-E \text { Transect } \\
210\end{array}$} & 0.46 & 0.095 & 2.1 & 0.39 \\
158 & 0.49 & 0.10 & 1.7 & 0.36 \\
114 & 0.51 & 0.11 & 1.3 & 0.32 \\
& & $I-4$ Transect & & \\
412 & 0.35 & 0.073 & 3.4 & 0.42 \\
272 & 0.30 & 0.062 & 2.5 & 0.29 \\
264 & 0.50 & 0.10 & 2.4 & 0.48 \\
\hline
\end{tabular}




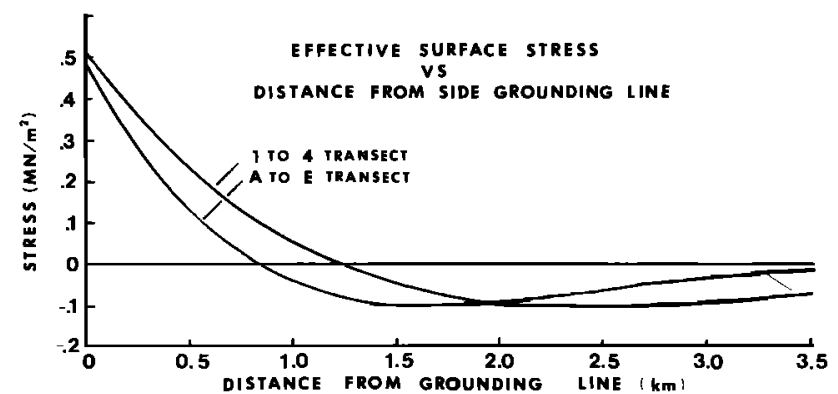

Fig. 9. Effective surface stress $\left(\sigma_{x}\right)_{H}$ versus distance from side grounding line.

ving front, and during this time, approximately 700 flexure cycles occur. Thus it is probable that fatigue failure causes effective thickness to decrease at the side grounding line as the ice moves downstream, so that tidal flexure contributes to breakup by progressively uncoupling the glacier from the fjord wall. In addition, a major structural weakness may exist along a line extending through points $1.7 \pm 0.4 \mathrm{~km}$ from the side grounding line near the calving front and $2.8 \pm 0.5 \mathrm{~km}$ from the side grounding line $2.6 \mathrm{~km}$ upglacier, if fatigue failure has caused deep cracking along the second flexure-induced stress maximum. The tidal flexure stresses analyzed here are, of course, only one component of the glacier's complex stress regime. Other stresses contributing to iceberg formation include Weertman creep stress [Weertman, 1957] and Reeh frontal bending stress [Reeh, 1968].

Acknowledgments. Thanks are extended to Robert H. Thomas, whose surveying expertise was instrumental in the success of the field survey and whose advice during data reduction is appreciated. Coast Guard pilots W. Hodges, D. Wallace, M. Stevens, and R. Ausness supported the survey under flying conditions that were sometimes difficult. Valuable field assistance was provided by Q. Robe, H. Gehring, and the Coast Guard cadets from the icebreaker Westwind. Thanks are extended to Charles $R$. Bentley for critically reviewing the manuscript. This study was supported by National Science Foundation grant DPP77-07806 and the United States Coast Guard. Additional support was provided by a faculty research grant from the University of Maine at Orono, and the Geophysical and Polar Research Center, University of Wisconsin at Madison. Susan Smith drafted the figures.

\section{REFERENCES}

Carbonnell, M., and A. Bauer, Exploitation des couvertures photographiques aériennes répétées du front des glaciers vêlant dans Diske Bugt en Umanak Fjord, Juin-Juillet, 1964, Medd. Groenl., 173(5), 1-78, 1968.

Dieter, G. E., Mechanical Metallurgy, 774 pp., McGraw-Hill, New York, 1976.

Glen, J. W., The creep of polycrystalline ice, Proc. $R$. Soc. London, Ser. A, 228, 519-538, 1955.

Higashi, A., S. Mae, and A. Fukuda, Strength of ice single crystals in relation to the dislocation structure, Proc. Int. Conf. Strength Metals Alloys 1967, 784-789, 1968.

Holdsworth, G., Flexure of a floating ice tongue, J. Glaciol., 8, 385$397,1969$.

Holdsworth, G., Tidal interaction with ice shelves, Ann. Geophys., 33(1/2), 133-146, 1977.

Hughes, T., Elastic and viscoplastic tidal flexure of floating ice, a study prepared for the Greenland Outlet Glacier Survey, U.S. Coast Guard, New London, Conn., 1972.

Hughes, T., The West Antarctic ice sheet: Instability, disintegration, and initiation of ice ages, Rev. Geophys. Space Phys., 13, 502-526, 1975.

Hughes, T., West Antarctic ice streams, Rev. Geophys. Space Phys., 15, $1-46,1977$.

Lingle, C. S., Tidal flexure of Jakobshavns Glacier, West Greenland, M.S. thesis, 151 pp., Univ. of Maine, Orono, 1978.

Popov, E. P., Mechanics of Materials, 441 pp., Prentice-Hall, Englewood Cliffs, N. J., 1952.

Reeh, N., On the calving of ice from floating glaciers and ice shelves, J. Glaciol., 7, 215-232, 1968.

Rink, H., Danish Greenland, Its People and Its Products, 468 pp., Henry S. King, London, 1877.

Robin, G. de Q., Glaciology III: Seismic shooting and related investigations, Sci. Result. Norw. Br. Swed. Antarct. Exped., 1949-1952, 5, 122-125, 1958.

Weertman, J., Deformation of floating ice shelves, J. Glaciol., 3, 38$42,1957$.

(Received April 8, 1980;

revised December 29, 1980; accepted January 16, 1981.) 